\title{
A possible case of prophylactic supra-inion trepanation in a child cranium with an auditory deformity (pre-Columbian Ancon site, Peru)
}

\author{
Katsutomo KATO $^{1 *}$, Ken-ichi SHINODA ${ }^{2}$, Yoshikazu KitAGAwA ${ }^{3}$, Yoshitaka MANABE ${ }^{3}$, \\ Joichi OYAMADA ${ }^{3}$, Kazunari IGAWA ${ }^{3}$, Hild VIDAL ${ }^{4}$, Atsushi ROKUTANDA ${ }^{3}$ \\ ${ }^{1}$ Department of Physical Therapy, Health Sciences, Nagasaki University Graduate School of Biomedical Science, \\ 1-7-1 Sakamoto, Nagasaki, 852-8520 Japan \\ ${ }^{2}$ Department of Anthropology, National Museum of Nature and Science, Tokyo, Japan \\ ${ }^{3}$ Department of Oral Anatomy and Dental Anthropology, Medical and Dental Science, \\ Nagasaki University Graduate School of Biomedical Science, Nagasaki, Japan \\ ${ }^{4}$ Division of Anthropology, National Museum of Archaeology, Anthropology and History of Peru, Lima, Peru
}

Received 26 November, 2006; accepted 2 May, 2007

\begin{abstract}
We had the opportunity to examine a pre-Columbian Peruvian child (about 4-5 years old) cranium with a healed lesion above the inion on the occiput. It has previously been claimed that suprainion lesions represent traces of prehistoric trepanation for ritual or prophylactic reasons in childhood, a practice termed 'trepanation supra-iniana'. An alternative hypothesis claimed that such lesions mainly result from abnormal long-term compression caused by artificial deformation. We describe several macroscopic characteristics of the cranium and discuss the claim that it is a case of 'trepanation supra-iniana'. The cranium is also characterized by an artificial anterior-posterior deformation, unilateral stenosis of the external auditory canal on the right side, and small drill holes on this same side in the frontal region. The supra-inion lesion, consisting of a shallow depression and a fissure-like orifice, is located slightly to the right on the occiput. The morphological-pathological state of the lesion is analogous to the healing of a trepanation by scraping. These observations suggest that the lesion did not result from artificial compression by head deformation, but from the infliction of trepanation identical to 'trepanation supra-iniana'. The observed stenosis of the external auditory canal is clearly congenital. It is considered that this clearly visible auditory deformity was the primary reason for conducting the ritual or prophylactic trepanation. The small drill holes in the frontal region may have been a post-mortem or peri-mortem trepanation of a ritual or superstitious nature.
\end{abstract}

Key words: Peruvian, child cranium, trepanation supra-iniana, ritual, aural deformity

\section{Introduction}

Trepanation is possibly one of the earliest forms of cranial surgical intervention of which we have any authentic record, and its practice is widely spread in space and time and continues to the present day (Lisowsky, 1967). Peru is recognized as a major source of ancient trepanned crania, the earliest of which, from a cemetery at the site of Paracas on the south coast, date back to approximately $400 \mathrm{BC}$ to 200 AD (Verano, 2003). The possible reasons for trepanation have been the subject of much debate, without a consensus being reached. In ancient Peru, trepanation clearly served as a practical treatment for cranial trauma and depressed fracture (Stewart, 1957; Weiss, 1958; Kato et al., 2002; Verano, 2003), and in addition may have been performed, in a magico-therapeutic context, to treat a variety of intracranial and psychiatric disorders, such as headache, vertigo, neuralgia, coma, delirium, intracranial vascular ca-

* Corresponding author. e-mail: k-katou@nagasaki-u.ac.jp phone: +81-95-849-7946; fax: +81-95-849-7946

Published online 30 June 2007

in J-STAGE (www.jstage.jst.go.jp) DOI: 10.1537/ase.061126 tastrophe, meningitis, convulsions, epilepsy, and intracranial tumors (Asenjo, 1963; Campillo, 1984; Velasco-Suarez et al., 1992; Marino and Gonzales-Portillo, 2000). Mann (1991) reported a case in which chronic ear disease was a possible reason for trepanation.

Cabieses, a Peruvian pathologist, proposed the existence in Peru of a special type of trepanation inflicted in a particular cranial region in childhood (Lastres and Cabieses, 1959). Weiss (1958), in a review of trephining practices in ancient Peru, reported that this type of trepanation had been found at several sites along the central coast of Peru, e.g. Chancay, Ancon and Makat-Tampu, where evidence of the usual type of trepanation, possibly for the purpose of treating cranial trauma or psychiatric disorders, as mentioned above, is lacking. Weiss called this type of trepanation, found only in young children, 'trepanation supra-iniana', because it is characterized by a depression and/or perforation in the bone made by scraping away the outer table of the occipital squama and is limited to the area above inion, where trepanations were not usually performed. As trepanation lesions received in childhood heal over time, it is relatively difficult to find any evidence of trepanation supra-iniana in adult crania. Weiss reported that among 133 subadult and adult crania 
from sites along the central coast, 59 cases showed traumatic traces at the supra-inion region, and among these 59 crania, $13(22 \%)$ belonged to 6- to 14-year-old children.

Weiss considered that the trepanation had both a ritualistic and a prophylactic significance, analogous to present-day Melanesian trepanation, which is intended to ward off future trouble from disease or trauma, and to promote longevity, thus possibly being an extension of surgical therapy for prophylaxis (Crump, 1901; Weiss, 1958). Since Weiss's description, the same type of trepanation has been reported from prehistoric sites in Mexico (Lagunas, 1974; VelascoSuarez et al., 1992; Christensen and Winter, 1997).

Stewart (1976), however, because of the seemingly high frequency with which supra-inion depressions and/or perforations occur in deformed crania with fronto-occipital flattening, considered that such lesions above the inion mainly occurred as a result of abnormal compression to the occiput by deformation. In recent years, discussion of the nature and significance of supra-inion lesions has languished.

We had the opportunity to examine a possible case of 'trepanation supra-iniana' in a cranium excavated from a pre-Columbian site in Peru. It was an artificially deformed child cranium with an orifice on the occipital squama above the inion, and with unilateral stenosis of the external auditory canal. In this paper, we describe several characteristics of the individual and discuss whether it truely belongs to the 'supra-iniana'category of trepanation.

\section{Materials and Methods}

The child cranium (Ancon No. 56, AI 7878) was housed in the National Museum of Archaeology, Anthropology and History of Peru (MNAAH), and was found by chance among 60 child crania from several pre-Inca sites along the central coast of Peru, consisting primarily of Ancon and MakatTampu sites. The other 59 crania showed no evidence of trepanning. The child cranium is one of a series of human skeletal remains collected from the great 'necropolis' (Ancon I, or Zone of Miramar) at Ancon, which is located on the central coast about $35 \mathrm{~km}$ north of Lima (Figure 1). This Ancon I site was excavated by Tello and colleagues from 1945 to 1948 , and probably dates from the Middle Horizon to the Late Intermediate Period, lasting from approximately 6501200 AD, according to the archives of J.C. Tello (19451965 ) held in the MNAAH (Rhode and Benfer, 2006).

The child is judged to have been $4-5$ years old at the time of death on the basis of dental eruption patterns (Schour and Massler, 1941). The gender remains unascertained. There are no associated infracranial remains. The cranium was photographed using a high-resolution digital camera (Nikon D100) at the Museum.

\section{Observations}

\section{General cranial morphology (Figure 2)}

The calvarium is in relatively good condition except that it lacks a small part of the right occipital bone surrounding the foramen magnum. The mandible has not been found. The cranium shows artificial deformation, with front-occipital flattening and lateral compensatory bulging of the parie-

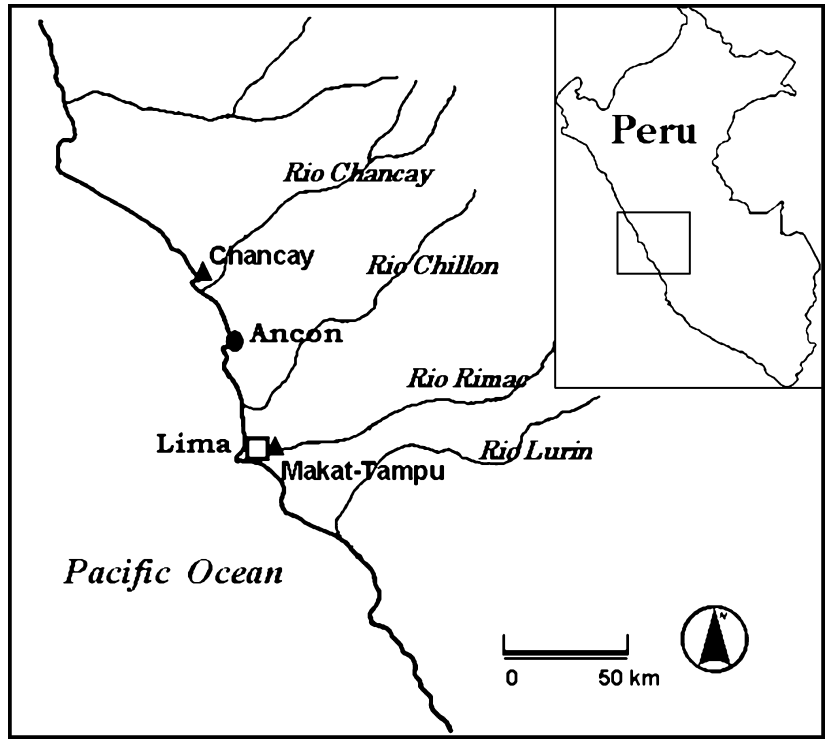

Figure 1. Map of the pre-Columbian Ancon site and two neighboring associated sites (Chancay and Makato-Tampu) located on the central coast about $35 \mathrm{~km}$ north of Lima.

to-temporal regions. Cranial dimensions are $142 \mathrm{~mm}$ maximum length and $151 \mathrm{~mm}$ maximum breadth, and the cranial index is 106.3, indicating hyperbrachiocephalic type. There is no asymmetry in the cranial morphology. All fontanels were already closed. The cranium has an isolated ossicle at lambda (os fonticuli posterior) and a medium-sized wormian bone on the left-side lambdoid suture.

Supra-inion lesion, possibly trepanation (Figure 2C, Figure 3)

Due to infancy, there is poor relief of the nuchal lines formed by musculature in the occipital region. Slightly to the right, on the occipital squama, is a shallow depression $20 \mathrm{~mm} \times 17 \mathrm{~mm}$, as if the outer layer has been scraped away. At the center of the depression is a horizontally aligned fissure-like orifice $11.7 \mathrm{~mm} \times 2.5 \mathrm{~mm}$. The edge of the orifice shows evidence of healing, and the outer surface of the depression surrounding the orifice shows a slight porotic change. These changes are analogous to the healing process after trepanation by the scraping method.

\section{Small holes in the frontal bone}

Almost at the right frontal tuber of the frontal bone are five small circular holes grouped together (Figure 2A, Figure 4). These are typical drill holes, measuring about $1.5 \mathrm{~mm}$ in diameter at the outer layer. Four of these are complete perforations, the remaining one penetrating only halfway. None of the margins of these holes show evidence of osseous reaction, so they are probably the work of a postmortem or peri-mortem operation.

\section{Auditory deformity}

A stenosis of the external auditory canal is detected on the right side of the cranium, as shown in Figure 5 and Figure 6 . The opening into the external auditory canal is cir- 


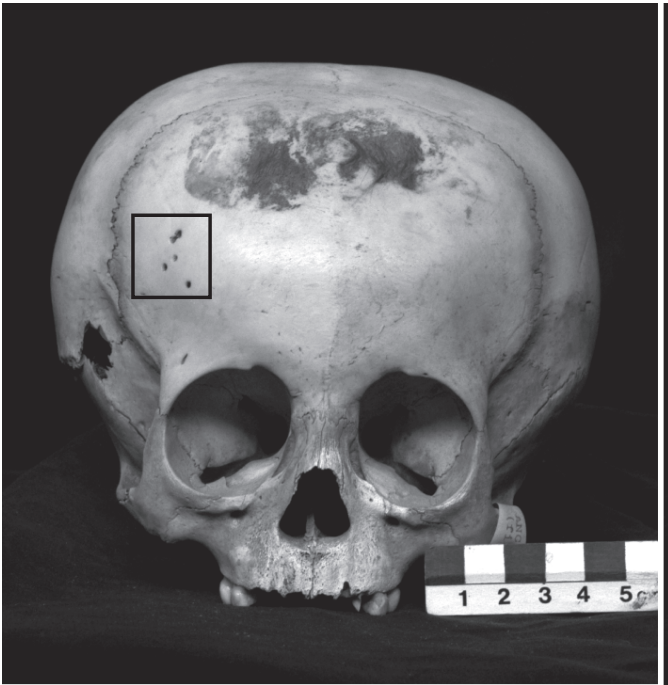

A. Frontal view

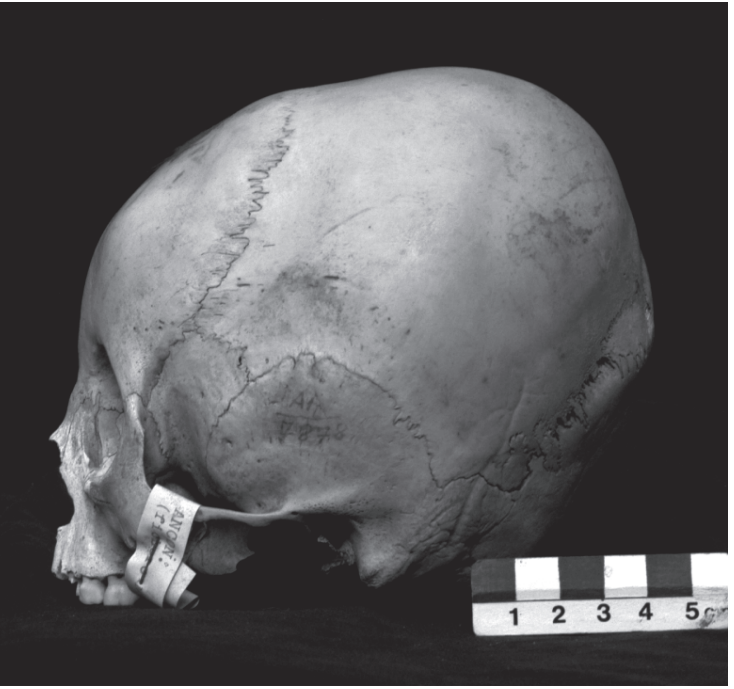

B. Lateral view (left)

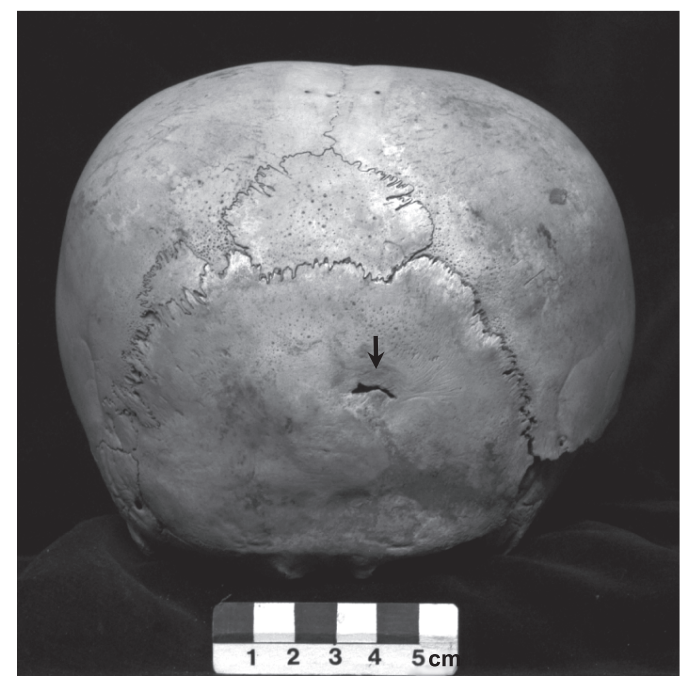

C. Posterior view

Figure 2. Child cranium with a supra-inion lesion (arrow in C), and small drill holes (surrounded by quadrangle in A) clustered together in the right frontal region.

cular and measures about $2.5 \mathrm{~mm}$ in diameter (Figure 5A). The canal is narrow throughout its entire course. The tympanic part of the temporal bone forming the surrounding wall of the external auditory canal is considerably underdeveloped. In particular, an image taken from the basal aspect of the cranium (Figure 6) shows that its anterior-posterior dimension is only about half that on the normal side. The tympanomastoid fissure is deep and distinct. These pathological features indicate that the child suffered from a congenital auditory deformity. Unfortunately a radiographic examination was not performed in Peru, and as a result what abnormalities there might have been of the tympanic cavity and the internal ear cannot be ascertained. The auditory tube is morphologically normal. In the glenoid fossa of the affected side, both the postglenoid process and articular tuberculum are rudimentary.
On the left side, the external auditory opening and canal are completely normal in size and in appearance (Figure 5B).

\section{Discussion}

Examples of cranial trepanations involving children are extremely rare, whatever the motives for the practice. In Verano's (2003) data from several areas of Peru, including a few central coast sites, of the 621 trepanned crania examined, none were of the supra-inion type, and $7.6 \%$ of the trepanations were subadult crania. As described above, in crania from sites along the central coast, Weiss (1958) found 13 subadult cases $(22 \%)$ that were possibly trepanned at the supra-inion region.

The present cranium of a child aged 4-5 years has several features in common with those exhibiting ritualistic supra- 


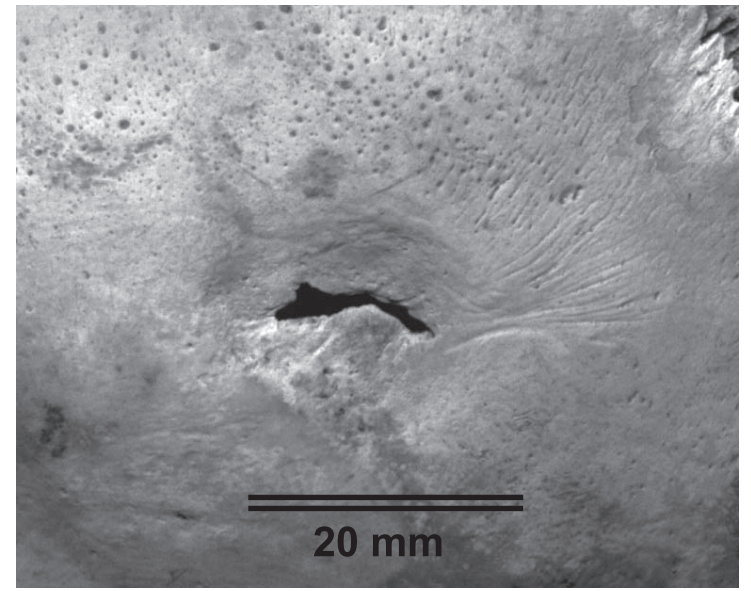

Figure 3. Supra-inion lesion consists of a shallow depression and a fissure-like orifice, with healing, in the occipital region. The lesion is located slightly to the right side of the median line of the skull.

inion trepanation as described by Weiss (1958) - the healed state of the lesion, its position on the occipital bone, and the geographical origin of the cranium.

Although Stewart (1976) proposed a competing interpretation that the lesion above the inion occurred as a result of long-term compression by the deforming practice, the slightly right-sided position of the supra-inion lesion in the present cranium, and the morphological-pathological condition very similar to that of healing after trepanation by scraping, probably contradict the assumption that this phenomenon results from compression.

No evidence clearly demonstrates whether the lesion is the result of an operation or bone reaction to the compression of cranial deformation. However, we regard the lesion as a result of the former procedure in view of the morphological changes, which are analogous to the healing process

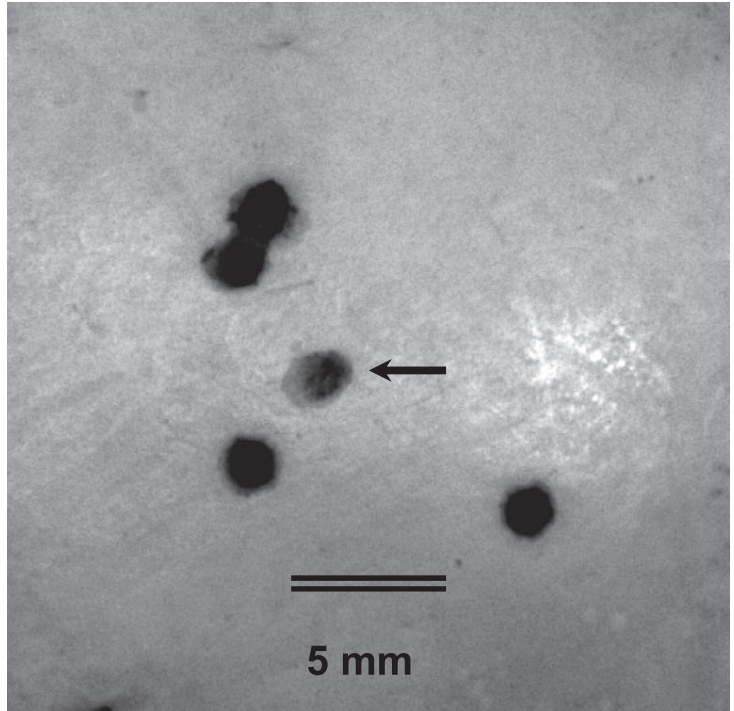

Figure 4. Five drill holes on the right-side of the frontal region. One of which (arrow) is unpierced. They show no healing reaction and were possibly post-mortem or peri-mortem perforations.

with slight porotic changes.

In connection with the unilateral stenosis of the external auditory canal on the right side, the supra-inion orifice may have also been deliberately trepanned slightly to the right of the midline. This auditory deformity is a rare condition. Stenosis and atresia may be acquired or congenital in origin. Acquired stenosis is usually the result of infectious inflammation and consists of a soft tissue plug rather than a bony plate (Jacobsen and Mills, 2006), so in the present case the condition was clearly congenital. To date there have been no reports of stenosis in ancient Peru, although Hrdlička (1933) reported seven cases of atresia of the external auditory canal.

Deformities of the external ear, including congenital

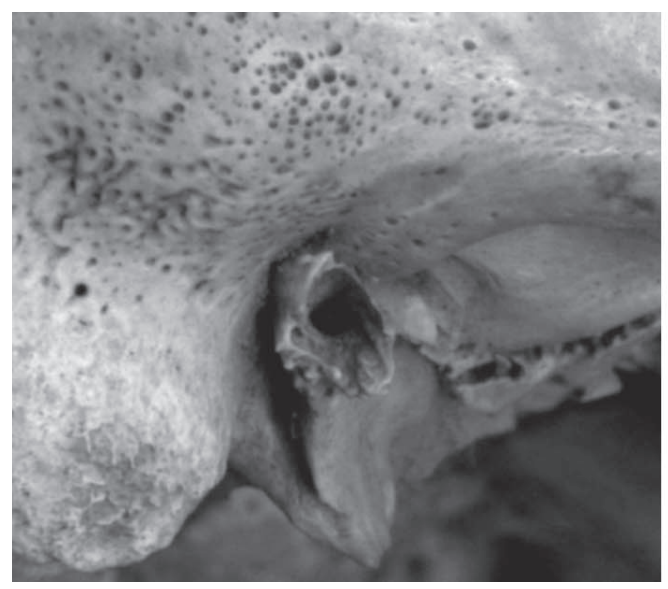

A. The right side

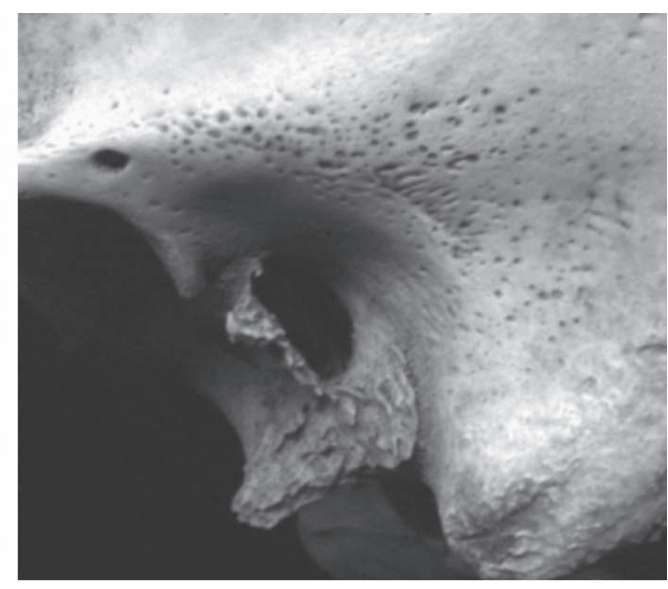

B. The left side

Figure 5. Openings of the external auditory canal. A. The right side. The opening and canal are strongly stenosed. B. The left side. The opening and canal are normal in size and appearance. 


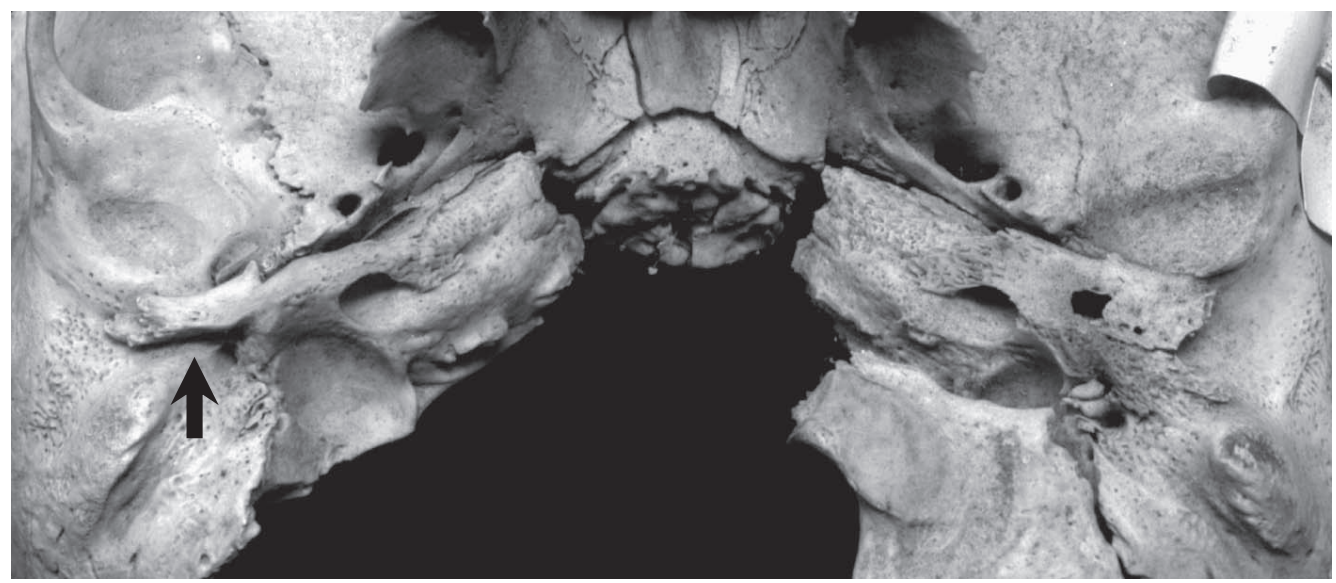

Figure 6. The basal view of the temporal bone. On the right side, the tympanic bone (arrow) is undeveloped, indicating a congenital deformity, with stenosis of the external auditory canal. On the left side, the temporal bone is completely normal in size and appearance.

stenosis, originate in developmental defects of the branchial arches. They can occur alone or in association with genetically determined syndromes (Karmody and Annino, 1995; Masnicová and Benuš, 2001). Because this case is represented only by the cranium, we are unable to identify the other deformities that occur in conjunction with stenosis. External auditory canal stenosis and atresia are usually accompanied by an auricular deformity called microtia (Okajima et al., 1996). Therefore, the infant examined might have had unilateral microtia or the associated visible physical abnormalities, though probably epxerienced little functional acoustic difficulties in his or her daily life.

This suggests that the auditory deformity was the primary reason for the trepanation in the present case. We consider it likely that the trepanation above the inion was also prophylactically administered with the intention of warding off future trouble from diseases, or with the hope of longevity.

The small drill holes on the side of the cranium exhibiting an auditory deformity showed no evidence of healing reaction. They may represent post-mortem or peri-mortem trepanations, though the motive remains uncertain. The suprainiana lesions were likely made at an interval of several years before the frontal holes were perforated. Although several cases of multiple trepanations on a single skull have been reported (Allison, 1976; Verano, 2003), we have found no satisfactory explanation of this form of trepanation. There is little doubt that the significance of the frontal holes differs from the trepanation supra-iniana, which is limited to the area above the inion. We consider that the peri-mortem operation was performed for therapeutic or magico-therapeutic aids, although we cannot, of course, exclude the possibility that stress from this operation led to the death of the child. In contrast, trepanation post-mortem can undoubtedly only have been magico-ritual in character (Campillo, 1984). Thus, in the present case, the holes may have been opened for a particular ritual or superstitious reason after death.

\section{Acknowledgments}

We thank the National Museum of Archaeology, Anthropology and History of Peru for permitting us to study skeletal materials in their possession. In particular, we are grateful to the staff of the Anthropology Division of the Museum for their cooperation during the investigation. This research was supported by the National Museum of Nature and Science, Tokyo.

\section{References}

Allison M.J. (1976) Treatment of head wounds in pre-Columbian and colonial Peru. MCV Quarterly, 12: 74-79.

Asenjo A. (1963) Neurosurgical techniques. Charles C. Thomas, Springfield, IL, pp. 20-26.

Campillo D. (1984) Neurosurgical pathology in prehistory. Acta Neurochirurgica, 70: 275-290.

Christensen A.F. and Winter M. (1997) Culturally modified skeletal remains from the site of Huamelulpan Oaxaca, Mexico. International Journal of Osteoarcheology, 7: 467-480.

Crump J.A. (1901) Trephining in the South Seas. The Journal of the Anthropological Institute of Great Britain and Ireland, NS, 31: 167-173.

Hrdlička A. (1933) Seven prehistoric American skulls with complete absence of external auditory meatus. American Journal of Physical Anthropology, 17: 355-377.

Jacobsen N. and Mills R. (2006) Management of stenosis and acquired atresia of the external auditory meatus. Journal of Laryngology and Otology, 120: 266-271.

Karmody C.S. and Annino D.J. (1995) Embryology and anomalies of the external ear. Facial Plastic Surgery, 11: 251-256.

Kato K., Vidal H., Shinoda K., Manabe Y., Kitagawa Y., Oyamada J., and Rokutanda A. (2002) Observation on the trepanned skulls with the traces of fractures in the ancient Peru. Bulletin of Nagasaki University School of Health Sciences, 15: 13-17 (in Japanese).

Lagunas R.Z. (1974) Observaciones recientes sobre la lesíon suprainiana. Boletín del Instituto Nacional de Anthropología e Historica Época 2, 11: 47-54.

Lastres J.B. and Cabieses F. (1959) La trepanacion del craneo en el antiguo Peru. Anales de la Faculitad de Medicina, Universidad Nacional Mayor de San Marcos, Lima, 42: 258-320. 
Lisowsky F.P. (1967) Prehistoric and early historic trepanation. In: Brothwell D. and Sandison A.T. (eds.), Diseases in Antiquity. Charles C. Thomas, Springfield, IL, pp. 651-672.

Mann G. (1991) Chronic ear diseases as a possible reason for trephination. International Journal of Osteoarcheology, 1: $165-168$.

Marino R. and Gonzales-Portillo M. (2000) Preconquest Peruvian neurosurgeons: A study of Inca and pre-Columbian trepanation and the art of medicine in ancient Peru. Neurosurgery, 47: 940-950

Masnicová S. and Benuš R. (2001) Atresia of an external acoustic meatus in an individual from historical Bratislava (Slovakia). Anthropological Science, 109: 315-323.

Okajima H., Takeichi Y., Umeda K., and Baba S. (1996) Clinical analysis of 592 patients with microtia. Acta Otolaryngology, Suppl. 525: 18-24.

Rhode M.P. and Benfer R.A. (2006) Proyecto de investigacion: Análisis de anthoroplogía físíca de 35 esqueletos correspondientes Ancón I (Zona Alta o Miramar)., Informe preliminar Diciembre 2006, Universidad Missouri-Colombia, Columbia, pp. $1-12$.
Schour I. and Massler M. (1941) The development of the human dentition. Journal of American Dental Association, 28: 1153 1160.

Stewart T.D. (1957) Stone age skull surgery: A general review with emphasis on the new world. Annual Report Smithsonian Institution, 107: 469-491.

Stewart T.D. (1976) Are supra-inion depressions evidence of prophylactic trepanation? Bulletin of the history of the medicine, 50: 414-434.

Velasco-Suarez M., Martinez J.B. Oliveros R.G., and Weinstein P.R. (1992) Archaeological origins of cranial surgery: Trepanation in Mexico. Neurosurgery, 31: 313-319.

Verano J.W. (2003) Trepanation in prehistoric South America: geographic and temporal trends over 2,000 years. In: Arnott R, Finger S and Smith C.U.M. (eds.), Trepanation: History, Discovery, Theory. Swets \& Zeitlinger Publishers, Lisse, pp. 223-236.

Weiss P. (1958) Osteologia cultural: Practicas cefálicas. 1a Parte. Cabeza trofeos, trepnaciones, cauterizaciones, Anales de la Facultad de Mediciana, Universidad Nacional Mayor de San Marcos, Lima, 41: 505-655. 